\title{
A study on factors influencing customer satisfaction: A case study of hospital dialysis patients
}

\author{
Zahra Jamalizadeh", Fattaneh Alizadeh Meshkani and Abdollah Naami
}

Department of Management, South Tehran Branch, Islamic Azad University, Tehran, Iran

\begin{tabular}{|c|c|}
\hline CHRON I C L E & A B S T RA C T \\
\hline $\begin{array}{l}\text { Article history: } \\
\text { Received May 20, } 2013 \\
\text { Received in revised format } \\
12 \text { August } 2013 \\
\text { Accepted } 7 \text { September } 2013 \\
\text { Available online } \\
\text { September } 82013 \\
\text { Keywords: } \\
\text { Customer satisfaction } \\
\text { Hospital patients } \\
\text { ANP }\end{array}$ & $\begin{array}{l}\text { Quality of services is considered as one of the most important factors for customer retention as } \\
\text { well as having a healthy business. In this paper, we present an empirical investigation to } \\
\text { determine the most important factors influencing patients' satisfaction in one of Iranian } \\
\text { hospitals. The proposed model of this paper uses fuzzy analytical network process (FANP) to } \\
\text { rank different factors. The proposed model considers four major criteria including employee, } \\
\text { management as well as organization, physicians and nurses. Our survey indicates that } \\
\text { management and organizational issues are the most important factors followed by issues } \\
\text { associated with physicians, nurses and employees. In terms of management and organization, } \\
\text { waiting time to receive services is the most important factor followed by geographic location of } \\
\text { the hospital, peaceful and quiet environment and quality of services. In addition, our surveyed } \\
\text { patients expected their patients to listen to them very carefully and this is the most important } \\
\text { item. They also expect nurses to provide a fast and reliable response while they expect } \\
\text { employees to treat them with respect. }\end{array}$ \\
\hline
\end{tabular}

(c) 2013 Growing Science Ltd. All rights reserved.

\section{Introduction}

These days, there is an increase in competition in different industries especially in healthcare industry. The increase in competition requires an increase in quality of services for better customer retention. However, one primary question is to find important factors influencing patients when they use different services in hospitals. There are normally different criteria and some of them may be in conflict. Therefore, we need to use multi criteria decision making (MCDM) techniques to find influential factors and to rank them, accordingly. Analytical network process (ANP) is one of the popular MCDM techniques for ranking different alternatives. The method is an extension of analytical hierarchy process where inter-relationship between various alternatives are also taken into account (Saaty, 1996, 2004; Ware et al., 2012).

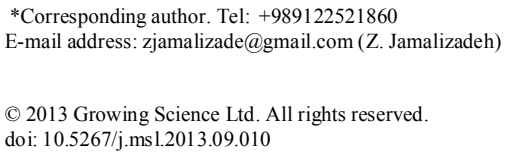




\section{The proposed method}

Many MCDM techniques do not deal with the interdependences among elements and to handle such problem, ANP as a new MCDM method was proposed by Saaty (1996). Saaty (1999) has demonstrated various kinds of ANP models, such as the Hamburger Model, the Car Purchase BCR model, and the National Missile Defense model. The proposed model of this paper recommends a modified Feedback System model (Fig. 1) that permits inner dependences within the criteria cluster, in which the looped are signifies the inner dependences.

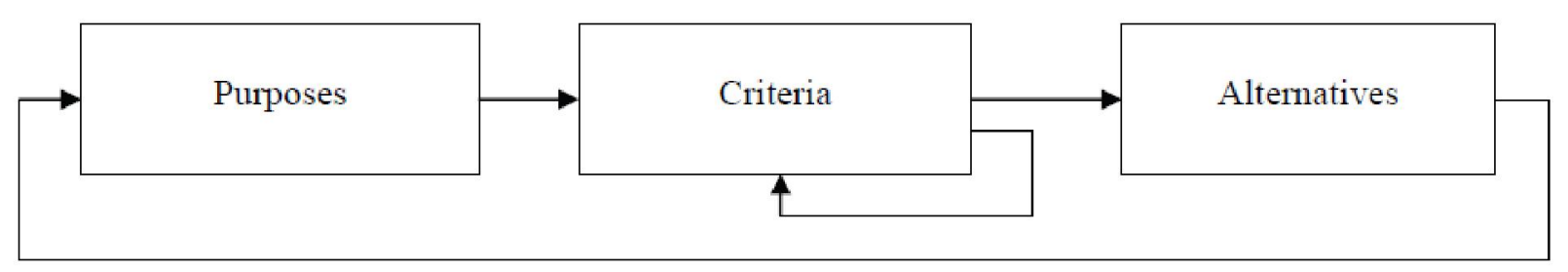

Fig.1. Feedback system model

To calculate the relative importance among elements, decision makers are asked to reply through a series of pair-wise comparisons. These pair-wise comparisons are normally based on the Saaty's nine-point scale 1-9. For assessing the weights of elements, the AHP applies the principal eigenvector of comparison matrix, whereas the ANP applies the limiting process method of the powers of the super-matrix (Sekitani \& Takahashi, 2001). When we ask decision maker to express his/her opinions, there may be some uncertainties associated with his/her insights. Therefore, we may use fuzzy numbers to handle uncertainty.

Afsharkazemi et al. (2012) used Fuzzy ANP in an application of quality function deployment (QFD) for ranking various alternatives. They used fuzzy matrix and house of quality to study the products development in QFD and also the second phase i.e. part deployment. In most researches, the primary objective was only on CRs to implement the quality function deployment and some other criteria such as production costs, manufacturing expenditures etc. were disregarded. The results of implementing fuzzy analysis network process based on the QFD model in Daroupat packaging firm to develop PVDC demonstrated that the most important indexes were being waterproof, resistant pill packages, and production cost.

Alvandi et al. (2012) proposed an integrated MCDM technique in ranking BSC perspectives and key performance indicators (KPIs) using a hybrid of decision making trial and evaluation laboratory (DEMATEL) and (ANP) techniques. Fazli and Jafari (2012) used a combination of ANP and DEMATEL techniques for investment purposes. Serkani et al. (2013) implemented a hybrid of AHP and ANP approaches for selecting improvement projects of Iranian Excellence Model in healthcare sector. Lin and Tsai (2009) developed an expert selection system to choose ideal cities for medical service ventures. They proposed an effective method based on the ANP combined with the technique for order preference by similarity to ideal solution (TOPSIS) to help medical service inventors who look for evaluating and selecting proper city.

The proposed model of this paper uses analytical network process to rank different factors influencing patient satisfaction. Fig. 2 demonstrates the framework of our study. As we can observe from Fig. 2, patient's satisfaction depends on four criteria including employees who work for hospital, management and organization, physicians and nurses. In terms of the first criterion, employee, there are five sub-criteria, which are general sanitary standards, rate of response, respect for patients, patient reception policies and regulation as well as release policies. In terms of 
management and organization specifications, there are four criteria including geographical location of hospital, waiting time to receive services, quality of services and peaceful and quite environment.

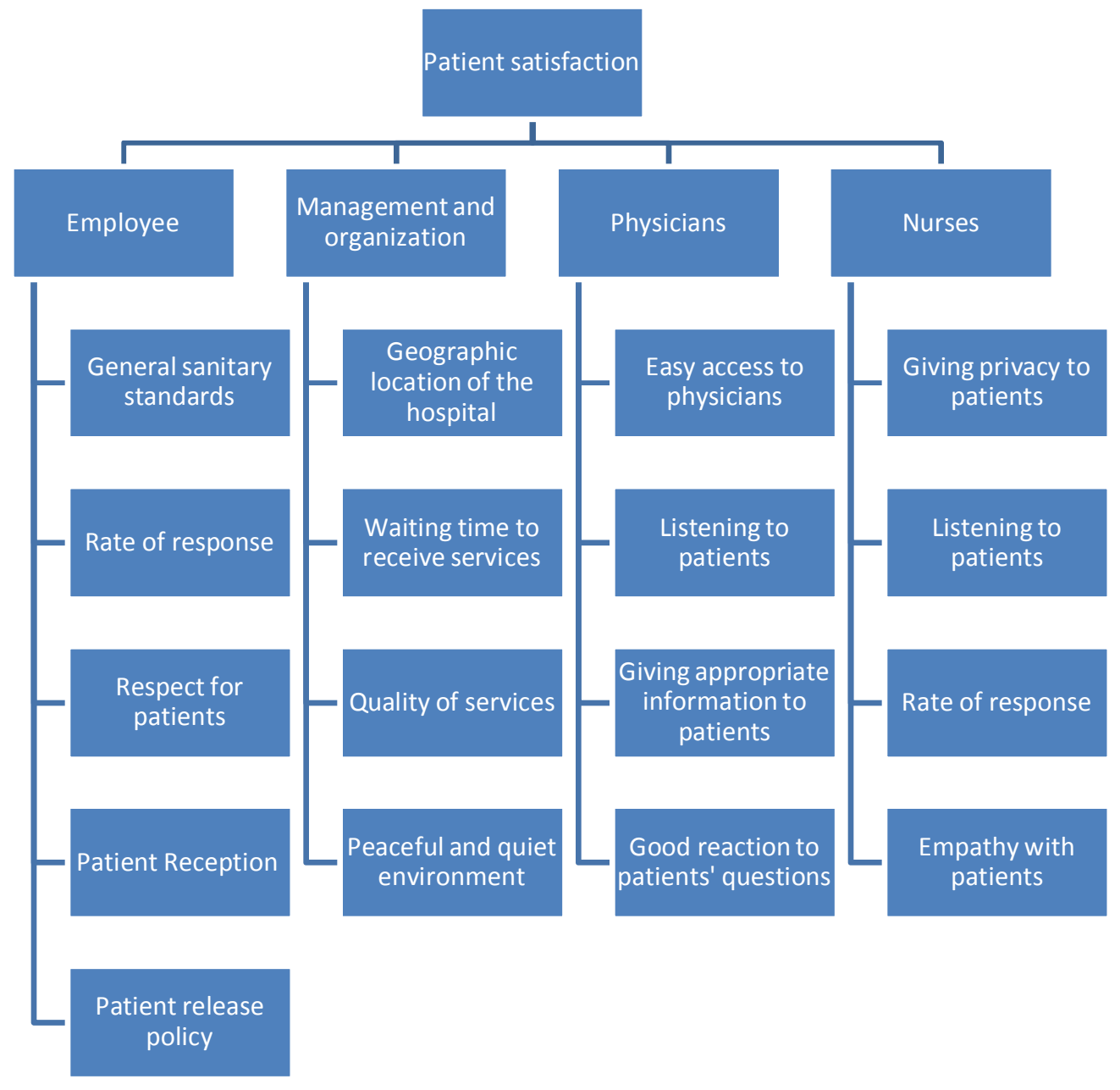

Fig. 2. The proposed framework of the study

Physicians is the third criterion in our study and it includes four criterion including the easy access, how good they listen to patients, how appropriate the responses are to patients and good reaction to patients' questions. Finally, nurses are the last criterion in our survey and this includes four criteria including giving privacy to patience, listening to patience, rate of response and empathy with patients.

We have asked some experts including different groups of people who could share their thoughts on the relative importance of various criteria based on pair-wise comparison. The process uses fuzzy analytical network process (FANP) to measure the relative importance of each criterion against the other one. The proposed study of this paper uses triangular numbers to express the relative weights. The procedure normalizes the numbers through the process to make sure that the numbers would maintain appropriate scaling systems.

\section{The results}

In this section, we present details of our survey on measuring the relative importance of each criteria based on the implementation of FANP. We first present details of ranking four major criteria in Table 1 as follows, 


\section{Table 1}

The summary of ranking four main criteria using FANP

\begin{tabular}{lc}
\hline Item & Weight \\
\hline Management and organizational issues & $(0.55,0.76,0.94)$ \\
Issues associated with physicians & $(0.31,0.39,0.50)$ \\
Issues associated with nurses & $(0.30,0.38,0.48)$ \\
Issues related to employees & $(0.14,0.17,0.27)$ \\
\hline
\end{tabular}

The results of Table 1 demonstrate that management and organizational issues are the most important factors followed by issues associated with physicians, nurses and employees.

\subsection{The relative weights of criteria associated with employees}

The first criterion, employee based items, include five sub-criteria and Table 2 demonstrates details of our survey for ranking various options.

\section{Table 2}

The results of the implementation of FANP for ranking employee based sub-components

\begin{tabular}{lccc}
\hline Criteria & \multicolumn{3}{l}{ Weight } \\
\hline General sanitary standards & 0.30 & 0.53 & 0.62 \\
Rate of response & 0.12 & 0.19 & 0.26 \\
Respect for patients & 0.59 & 0.79 & 0.88 \\
Patient Reception & 0.18 & 0.28 & 0.41 \\
Patient release policy & 0.31 & 0.42 & 0.54 \\
\hline
\end{tabular}

The results of Table 2 show that respect is the most important factor and they expect employees to treat them with respect. Most patients believe that the hospitals must be clean and follow standards and regulation to take care of the hospitals, properly. The third influential factor is associated with patient release policy followed by patient reception.

\subsection{The relative weights of criteria associated with nurses}

The second criterion is associated with nurses who are working in hospitals and it includes four subcriteria summarized in Table 3.

Table 3

The results of the implementation of FANP for nurses

\begin{tabular}{llrl}
\hline Criteria & \multicolumn{3}{c}{ Weight } \\
\hline Giving privacy to patients & 0.52 & 0.72 & 0.88 \\
Listening to patients & 0.07 & 0.21 & 0.33 \\
Rate of response & 0.73 & 0.85 & 0.92 \\
Empathy with patients & 0.17 & 0.29 & 0.44 \\
\hline
\end{tabular}

According to the results of Table 3, rate of response to patients is the most important factor followed by giving privacy to patients and empathy with patients.

\subsection{The relative weights of criteria associated with physicians}

The third criterion is associated with physicians who are working in hospitals and it includes four sub-criteria summarized in Table 4. 
Table 4

The results of the implementation of FANP for physicians

\begin{tabular}{llrl}
\hline Criteria & \multicolumn{3}{c}{ Weight } \\
\hline Easy access to physicians & 0.31 & 0.53 & 0.82 \\
Listening to patients & 0.63 & 0.87 & 0.96 \\
Giving appropriate information to patients & 0.13 & 0.21 & 0.37 \\
Suitable reaction to patients' questions & 0.24 & 0.41 & 0.61 \\
\hline
\end{tabular}

According to the results of Table 4, listening to patients is the most important factor followed by giving easy access to physicians, suitable reaction to patients and giving appropriate information to patients.

\subsection{The relative weights of criteria associated with organization and management}

The last criterion is associated with hospitals' management and organizational factors and it includes four sub-criteria summarized in Table 5.

\section{Table 5}

The results of the implementation of FANP for organizational issues and management

\begin{tabular}{lccc}
\hline Criteria & \multicolumn{3}{c}{ Weight } \\
\hline Geographic location of the hospital & 0.24 & 0.61 & 0.95 \\
Waiting time to receive services & 0.48 & 0.72 & 0.97 \\
Quality of services & 0.16 & 0.29 & 0.49 \\
Peaceful and quiet environment & 0.24 & 0.38 & 0.67 \\
\hline
\end{tabular}

According to the results of Table 5, waiting time to receive services is the most important factor followed by geographic location of the hospital, peaceful and quiet environment and quality of services.

\section{Conclusion}

In this paper, we have learned more about important factors influencing customer satisfaction in hospitals. The results of our survey have concluded that patients have different expectations from management, employees, physicians and nurses. While listening to patients is the most important issue for physicians, they expect employees to treat them with respect and they expect nurses to provide high quality services as quickly as possible. Finally, patients expect the officials of hospitals to reduce waiting time for their services.

\section{Acknowledgment}

The authors would like to thank the officials of Kamkar hospital in city of Qom, Iran for cordially cooperating in accomplishment of this survey. We are also delighted for constructive comments on earlier version of this paper.

\section{References}

Afsharkazemi, M.A., Khodabakhsh, M., \& Motadel, M.R. (2012). Applying fuzzy analytic network process in quality function deployment model. Management Science Letters, 2(4), 1325-1340. 
Alvandi, M., Fazli, S., Yazdani, L., \& Aghaee, M. (2012). An Integrated MCDM Method in Ranking BSC Perspectives and key Performance Indicators (KPIs). Management Science Letters, 2(3), 995-1004.

Fazli, S., \& Jafari, H. (2012). Developing a hybrid multi-criteria model for investment in stock exchange. Management Science Letters, 2(2), 457-468.

Lin, C. T., \& Tsai, M. C. (2009). Development of an expert selection system to choose ideal cities for medical service ventures. Expert Systems with Applications, 36(2), 2266-2274.

Saaty, T. L. (1996). The analytic network process-decision making with dependence and feedback. Pittsburgh, PA: RWS Publications.

Saaty, T. L. (2004). Decision making - the analytic hierarchy and network processes (AHP/ANP). Journal of systems science and systems engineering, 13(1), 1-35.

Sekitani, K., \& Takahashi, I. (2001). A unified model and analysis for AHP and ANP. Journal of the Operations Research Society of Japan, 44(1), 67-89.

Serkani, E. S., Mardi, M., Najafi, E., Jahanian, K., \& Herat, A. T. (2013). Using AHP and ANP approaches for selecting improvement projects of Iranian Excellence Model in healthcare sector. African Journal of Business Management, 7(23), 2271-2283.

Ware, N.R., Sing, S.P., \& Banwet, D.K. (2012). Supplier selection problem: A state-of-the-art review. Management Science Letters, 2(5), 1465-1490. 